\title{
Exploring Graduate Students' Attitudes towards Team Research and Their Scholarly Productivity: A Survey Guided by the Theory of Planned Behavior
}

\author{
Tianlan Wei \\ Mississippi State University, \\ Mississippi State, MS, USA \\ ewei@colled.msstate.edu \\ Lucy Barnard-Brak and \\ Eugene W. Wang \\ Texas Tech University, \\ Lubbock, Texas, USA \\ lucy.barnard-brak@ttu.edu; \\ eugene.wang@ttu.edu
}

\author{
Alime N. Sadikova \\ South Hills High School, \\ Fort Worth, Texas, USA \\ alime.sadikova@fwisd.org
}

\author{
Dilshod Sodikov \\ Academy of Dallas, \\ Dallas, Texas, USA
}

denis.sodikov87@gmail.com

Abstract

This study explores the attitudinal and motivational factors underlying graduate students' attitudes towards team research. Guided by the Theory of Planned Behavior, we hypothesize that attitude, subjective norm, and perceived behavioral control are three major determinants of graduate students' intentions to conduct team research. An instrument was developed to measure the influences of these factors on students' intentions and relevant scholarly productivity. A total of 281 graduate students from a large, comprehensive university in the southwest United States participated in the survey. Descriptive statistics reveal that around two-thirds of graduate students have no co-authored manuscripts submitted for publication since they started graduate school. Factor analyses validated the factor structure of the instrument, and the results of Structural Equation Modeling show that (a) graduate students' attitudes towards team research have a positive correlation with their attitudes towards individual research; (b) attitude towards

Material published as part of this publication, either on-line or in print, is copyrighted by the Informing Science Institute. Permission to make digital or paper copy of part or all of these works for personal or classroom use is granted without fee provided that the copies are not made or distributed for profit or commercial advantage AND that copies 1) bear this notice in full and 2) give the full citation on the first page. It is permissible to abstract these works so long as credit is given. To copy in all other cases or to republish or to post on a server or to redistribute to lists requires specific permission and payment of a fee. Contact Publisher@InformingScience.org to request redistribution permission. team research, subjective norm, and perceived behavioral control, along with students' discipline/major areas and classification, account for $58 \%$ of the variance in the intention to conduct team research; and (c) subjective norm appears to be the most influential factor in the model, followed by attitude; while perceived behavioral control is not of much importance. These findings provide implications for academic 
departments and programs to promote graduate students' team research. Specifically, creating a climate for collaborative research in academic programs/disciplines/universities may work jointly with enhancing students' appraisals of such collaborations.

Keywords: graduate student, team research, scholarly productivity, the theory of planned behavior, attitude, subjective norm, perceived behavioral control, intention

\section{Introduction}

Graduate students' scholarly productivity is critical to their future careers. Graduate education is considered to "put a great emphasis on research skills and research-based decision making that is beyond the capabilities of most undergraduate students" (Moore, Tatum, \& Sebetan 2011, p. 67); Posselt and Black (2012) also noted that the mission of postgraduate education is the training of the next generation of researchers. Therefore, expectations are placed upon graduate students with regard to their scholarly productivity. For example, many leading academic departments have required their graduate students to publish at least one or two research articles in scholarly journals as part of their graduation requirements (Lei \& Chuang, 2009). Although universities may have different requirements for master's and doctoral students, Bourke and Holbrook (2013) indicated that their research theses are not evaluated using qualitatively different criteria, though doctoral students in general receive higher quality grading. Based on a U.S. sample consisting of both master's and doctoral students, Barrick, Easterly, and Rieger (2011) also found that the largest portion of these graduate students indicate their career goals to be in research and development. A graduate student, whether pursing a master's or doctorate degree, gets immersed in a research-oriented environment upon entering graduate school.

Naturally, these research-oriented environments differ in the level of collaboration. Collaboration is defined as "the coming together of diverse interests and people to achieve a common purpose via interactions, information sharing, and coordination of activities" (Jassawala \& Sashittal, 1998, p. 239). In a graduate school setting, new incoming students tend to be more technology advanced than the existing faculty, and the existing faculty and graduate student population is more diverse in terms of needs, expectations, backgrounds, and levels of commitment and interests. The acquisition of knowledge and skills is thereby an important function of collaboration, and graduate students may benefit from participating in team research. As Fox (1991) described research as a highly social and political process of communication, interaction, and exchange, graduate students may better fulfill their ambitions through participating in team research. With the involvement of graduate students, research teams are beneficial in terms of research output as well as students' personal developments. An example was given by Hilvers (2012) about the research teams at the Loyola University's Centre for Urban Research and Learning, which had completed 150 research projects since 1996. Most of these teams included community partners, faculty, graduate and undergraduate students, and staff. Graduate students were the ones who served as engines of these teams and faculty and community partners were there only when needed. Graduate students processed daily work, mentored undergraduate team members, contacted professors and community partners as needed, and worked closely with the staff of the Centre. Considering the cost of having professors and community partners do all research work and how little time they had, the Centre encouraged all parties to engage graduate students in research. Team research experiences provided a great opportunity for graduate students to learn by practice. Such practices are described by Hilvers (2012) as "throwing graduate students into the "deep end' of research as a way of teaching them to swim" (p. 22).

Every discipline has its own context and approach to graduate student preparation (Becher, 1984; B. R. Clark, 1987). Particularly, each program has its specific way of conducting research, keeping balance between teaching and research, and the level of collaboration among scholars. While a professor of history or English tends to conduct research alone, a professor of medicine or engi- 
neering is more likely to work with a group of colleagues or graduate students (Austin, 2002). Further, some graduate programs and students themselves build their graduate curricula based on societal expectations. For instance, while a doctoral student of chemistry will likely have a better chance to get a job if he or she has laboratory experiences of team research, a doctoral student of education will likely be more marketable if he or she has experience in teaching college level classes as well as first-author publications. Hence, research on collaborative research must take into account the disciplinary effects for addressing their focal questions.

\section{Theoretical Framework}

Our review of the literature revealed several issues in the field of team/collaborative research. First of all, the data of many studies were derived from personal reflections (e.g., Blumer, Green, \& Palmanteer, 2007; Bryan, Negretti, Christensen, \& Stokes, 2002; Lee \& Mitchell, 2011), thus being qualitative in nature. We consider quantitative investigations to be necessary to supplement the existing knowledge body. Next, the early studies have mostly focused on the scholarly productivity of university faculty (e.g., Blackburn, Behymer, \& Hall, 1978; Bland \& Ruffin, 1992; Bland \& Schmitz, 1986), and there are few investigations focusing on graduate students as a particular population. Even though the past two decades have witnessed the emergence of research on the collaborative research among undergraduate and graduate students, the bulk of the research attempts to identify team or environmental characteristics for productive, successful research teams. These characteristics include team organization and operation (e.g., Hulse-Killacky \& Robison, 2005; Lee \& Mitchell, 2011; Li, Zhu, \& Wang, 2010; Turner, 2006; Waldron, Shattuck, Zimbrick, Finter, \& Edwards, 2007), member characteristics (e.g., Blumer et al., 2007; Wan Mohamed, Omar, Ahmad, \& Juned, 2012), and process of bonding (e.g., Bryan et al., 2002). Arguably, these studies all assume the active roles of graduate students in team research while leaving out the graduate population who hover, still debating over the costs and benefits of team research. Hence, there appears to be a gap in research with regard to graduate students' decisions on whether or not to participate in research teams, specifically, whether they perceive team research as positive and beneficial experience in their academic lives.

While several theoretical perspectives are available for the present study, Bandura's $(1977,1986)$ social cognitive theory provides a most pertinent basis for our investigations. Based on our literature review, an individual researcher is influenced by both environmental and personal characteristics (Blackburn et al., 1978; Bland \& Ruffin, 1992; Cameron \& Blackburn, 1981). For example, Bland and Ruffin (1992) identified several characteristics of a productive research team such as distinctive culture, positive group climate, and concentration on recruitment and selection; in the meantime, a team member should also possess personal characteristics such as personal motivation, research training, early scholarly habits, socialization to academic values, network of productive colleagues, and resources (Bland \& Schmitz, 1986; S. M. Clark \& Corcoran, 1985). As such, the interplay between the environmental and personal factors is critical in understanding researchers' development through collaborative research. The social cognitive theory depicts people as self-organizing and proactive rather than merely reactive to social environmental or inner forces (Zimmerman \& Schunk, 2003). In addition to personal and environmental determinants, behaviors are also included in Bandura's (1977) triadic reciprocal causation model. As Bandura (1986) stated, "what people think, believe, and feel affects how they behave" (p. 25). Taken into the current context, graduate students' attitudes towards team research may affect how they organize personal and environmental resources to perform research activities. Graduate students' attitudes, appraisals, and other motivational factors are therefore worth researchers' attention.

Guided by the theory of planned behavior (TPB; Ajzen, 1988, 1991), the present study aimed to examine the attitudinal and motivational factors underlying graduate students' perception of team 
research and to explore how these factors may predict their decisions and behaviors. Closely related the social cognitive framework, the theory of planned behavior (TPB) was derived from the expectancy-value theory (Ajzen \& Fishbein, 1980; Atkinson, 1964), which was designed to account for the incentive motivation people use to guide their actions for acquiring corresponding outcomes of their behaviors. Essentially, the expectancy-value theory postulates that the strength of motivation is governed jointly by the expectation that particular actions will produce specified outcomes, and the perceived value of those outcomes (Bandura, 1997). The TPB took one step beyond the expectancy-value theory by adding a new component: perceived behavioral control. According to Ajzen (1991), the view of perceived behavioral control is most compatible with Bandura's $(1977,1982)$ concept of perceived self-efficacy. Self-efficacy is a key component in Bandura's (1997) social cognitive theory, which refers to beliefs in one's capabilities to organize and execute the courses of action required to produce given attainments. As Ajzen (1991) stated, the expectancy-value theory formulations were found to be only partly successful for predicting behaviors, and adding perceived behavioral control into the model helps predict behaviors with much higher accuracy.

Intention is a central factor in the TPB, which can be construed as the indication of how much effort individuals are planning to exert in order to perform the behavior (Ajzen, 1991). The higher the intention, the better chances of the behavior being performed are. In other words, intention is the immediate antecedent of the behavior. In the TPB, the three determinants of intention are named attitude towards the behavior, subjective norm, and perceived behavioral control (Ajzen, 1988, 1991). Attitude towards the behavior refers to an individual's evaluation or appraisal of the behavior; subjective norm refers to the perceived social pressure to perform or not to perform the behavior; and perceived behavioral control refers to the perceived level of difficulty of performing the behavior.

To date, the TPB has been widely used in social psychology to associate the way a person thinks with the resulting behaviors. Armitage and Conner (2001) meta-analyzed 185 TPB studies and found that the TPB accounted for $27 \%$ of the variance in behavior and $39 \%$ of the variance in intention. Similarly, Cooke and Sheeran (2004) meta-analyzed 44 TPB studies and reported that attitude, subjective norm, and perceived behavioral control accounted for 39 to $42 \%$ of the variance in intention, while intention and perceived behavioral control predicted between 28 to $34 \%$ of the variance in behavior. In the area of team/collaborative research, Li et al. (2010) adopted the TPB to explore the influencing factors of the intention to share tacit knowledge in the university research team. Their findings, however, are primarily concerned about one specific aspect of team research (i.e., share of tacit knowledge), thus bearing little relevance to the present study.

The present study was conducted to address to the following research questions:

1. What is the relationship between graduate students' attitudes towards individual research and their attitudes towards team research?

2. Does the theory of planned behavior (TPB) provide a viable formulation to account for graduate students' intentions and behaviors to produce research?

3. How do the predictors of the TPB (i.e., attitude, subjective norm, and perceived behavioral control) relate with each other and contribute to the outcome variables (i.e., intention and behaviors)?

We hypothesized, based on the literature, that (a) attitude towards individual research negatively correlates with attitude towards team research, (b) the TPB provides a viable model to account for graduate students' intention to produce research through teamwork, and (c) attitude towards team research, subjective norm, and perceived behavioral control are three indispensable determinants 
Wei, Sadikova, Barnard-Brak, Wang, \& Sodikov

of intention, and further, intention and perceived behavioral control significantly predict behaviors (Ajzen, 1991).

\section{Method}

\section{Participants}

A total of 281 participants from a large, comprehensive south-western university in the United States responded to our survey. The participants were gathered through either email notice or face-to-face recruitment to form a convenience sample. A large proportion $(37.7 \%, n=106)$ of our sample reported being international students and 34.2\% $(n=96)$ reported that they spoke English as a non-primary language. Among the participants, $50.2 \%(n=141)$ reported being master's students, $47.0 \%(n=132)$ being doctoral students, $0.8 \%(n=2)$ being "Others", and $2.1 \%(n=6)$ with classification data missing. The average age was 30.2 years old $(S D=10.2)$. Approximately $52.7 \%(n=148)$ of the participants were male, $44.8 \%(n=126)$ were female, and $2.5 \%(n=7)$ with gender information missing. In terms of ethnicity, 50.2\% $(n=141)$ reported being White, followed by 25.3\% $(n=71)$ Asian, 9.3\% $(n=26)$ Hispanic, 5.3\% $(n=15)$ African American, 6.0\% $(n=17)$ "Others," and 3.9\% $(n=11)$ with ethnicity information missing. Participants came from primarily two disciplines: engineering $(41.6 \%, n=117)$ and education $(38.8 \%$, $n=109)$. Other disciplines represented in this study were human sciences $(5.3 \%)$, architecture $(3.9 \%)$, agricultural sciences $(2.1 \%)$, arts and sciences $(1.4 \%)$, visual and performing arts $(1.1 \%)$, and business administration $(0.7 \%)$. Approximately 5.0\% $(n=14)$ of the participants did not have or endorse a major area.

\section{Measures}

A survey questionnaire was developed to collect academic/demographic information and measures of the TPB. The first section included questions regarding degree being pursued, major field, age, gender, ethnicity, international student status, and English proficiency. The second section included the TPB items designed to evaluate individuals' attitudes towards individual research, attitudes towards team research, subjective norms, perceived behavioral control, and intentions to produce research through teamwork. Finally, Behavior was indexed by the number of co-authored manuscripts the participant had submitted since he started graduate school.

The TPB items were developed based on Fishbein and Ajzen's (2010) suggestions on the construction of a TPB questionnaire. The behavior of interest was identified as publishing performance, specifically, the engagement in literature review, data collection, and manuscript preparation. Next, about 10 items were created for each TPB factor, and a content expert was recruited to assess the face validity and provide suggestions on wording changes. Finally, the items were piloted and a number of them were dropped because of limited relevance. As a result, 45 TPB items were retained. Participants were asked to rate each item on a 7-point bipolar adjective scale (e.g., 1-strongly disagree to 7-strongly agree, 1-worthless to 7-valuable, 1-very unimportant to 7very important).

\section{Procedure}

The data for this study were collected using both an online survey platform (SelectSurvey.NET) and scannable paper and pencil forms with identical question items. To balance the proportions of social science and applied science students, the target population mainly involved graduate students majoring in education or engineering. An email invitation with the link to the online survey was sent to graduate students, and questionnaires were also handed to graduate students in a face-to-face classroom setting. Participation in this study was completely anonymous and vol- 
untary. Approximately $49.8 \%(n=140)$ of the participants responded to the online survey and $50.2 \%(n=141)$ filled out our paper and pencil forms.

\section{Results}

\section{Descriptive Statistics}

All 281 participants reported having submitted a mean of 1.05 co-authored manuscripts for publication since they started graduate school $(S D=5.21)$. In terms of breakdown according to demographic background, males reported a mean of $0.82(S D=1.66)$ while females reported a mean of $1.39(S D=7.67)$; domestic students reported a mean of $1.14(S D=6.57)$ while international students reported a mean of $0.99(S D=1.78)$; master's students' reported a mean of $0.49(S D=$ $1.40)$ while doctoral students reported a mean of $1.76(S D=7.55)$. Nonetheless, these results must be interpreted with caution because the data were positively skewed at $p<.01$ (Field, 2009) with only a few participants $(n=12,4.3 \%)$ having over five co-authored submissions, as well as a majority of participants $(n=180,64.1 \%)$ having no submission at all. A less biased statistic was thus the median, which was 0 among all participants.

\section{Factor Analysis}

Prior to factor analysis, the data were screened for multicollinearity and multivariate outliers in SPSS v19. Bivariate correlation coefficients were computed among the 45 TPB items and there was no evidence of multicollinearity $(r>.80)$. Cook's distances were then computed and there were no significant multivariate outliers (Cook's distance > 1) (Cook \& Weisberg, 1982).

Exploratory factor analysis (EFA) is typically used earlier in the process of instrument development to determine the appropriate number of common factors (Brown, 2006). A principal axis factoring analysis (EFA) with promax rotation was conducted on the 45 items. Promax rotation allows for factors to be correlated (Field, 2009), and the assumption was made that the factors in the TPB model were related. To determine the number of factors, we examined both the eigenvalues (Kaiser, 1960) and the scree plot for points of inflection (Field, 2009). The initial analysis yielded 11 factors with eigenvalues greater than 1 . However, consistent with what was indicated by the inflection point, only six factors had eigenvalues greater than 1 after rotation. Using Gorsuch's (1997) criteria to count only the number of factors with three or more salient loadings (i.e., $|\lambda|>.40)$, we dropped the sixth factor with one salient factor loading. In addition, we dropped items that had salient loadings on more than one factor. A 5-factor simple structure was achieved as a result. The Kaiser-Meyer-Olkin measure verified the sampling adequacy for the analysis, $\mathrm{KMO}=.80$, which is between "good" and "great" according to Hutcheson and Sofroniou's (1999) criteria. All five factors in combination explained $51.30 \%$ of the variance. Table 1 shows the factor loadings after rotation and the internal consistency reliabilities (Cronbach's $\alpha$ ) of each factor. Except for Attitude towards Individual Research $(\alpha=.90)$, the other four factors were in line with the theory of planned behavior (TPB): Attitude towards Team Research $(\alpha=.89)$, Subjective Norm $(\alpha=.77)$, Perceived Behavioral Control $(\alpha=.76)$, and Intention to Produce Research through Teamwork $(\alpha=.82)$. In addition, Table 1 also presents the descriptive statistics which illustrate the shape of the distribution of each factor. All five factors appear to be negatively skewed, meaning that respondents tend to endorse the higher-order options of the items; but only the skewness of Attitude towards Team Research and Subjective Norm is statistically significant (Field, 2009). Nevertheless, the two factors still demonstrated sufficient disparity in their distributions as revealed by the histograms and boxplots. This solution used $32(71 \%)$ of the original 45 items. 


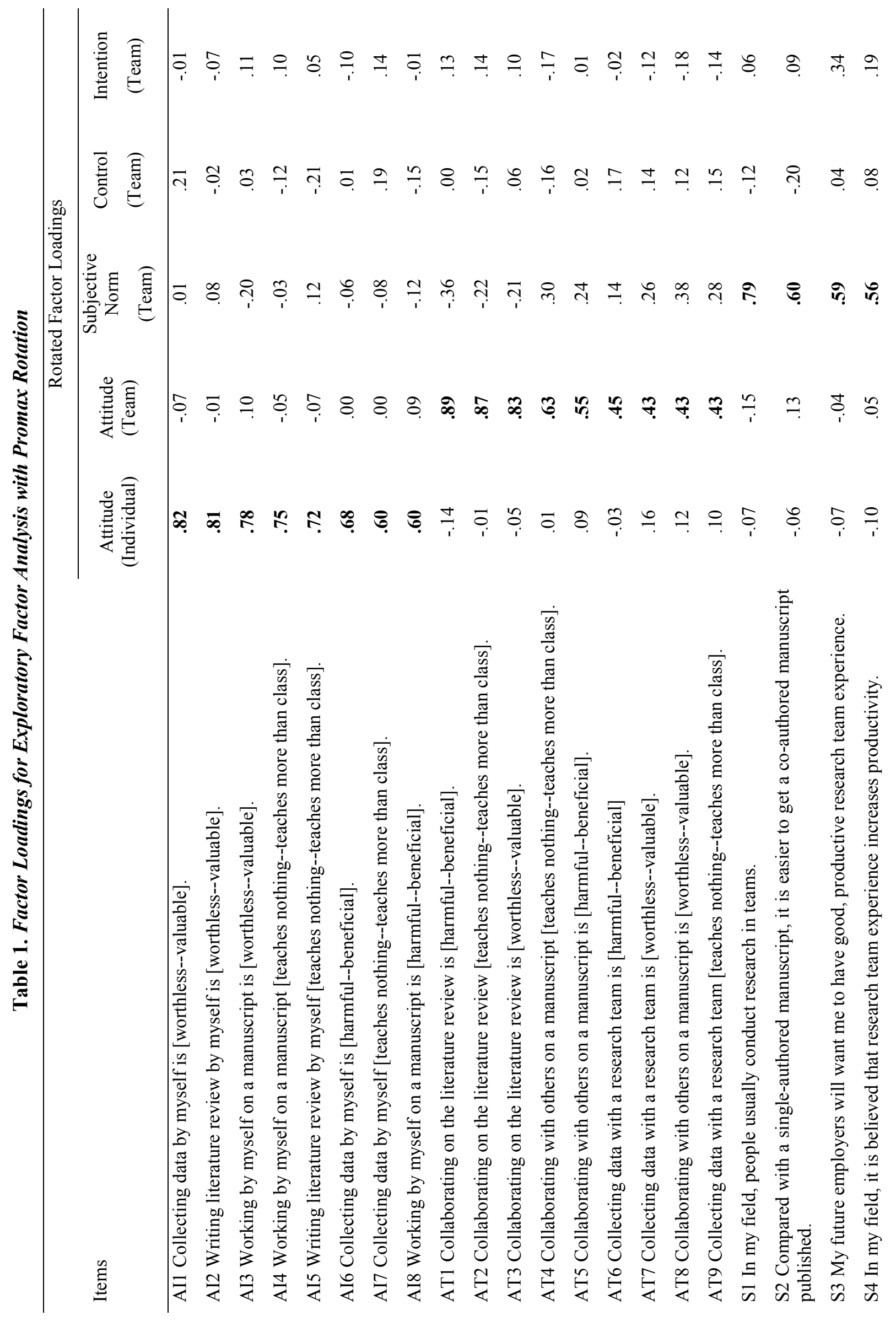




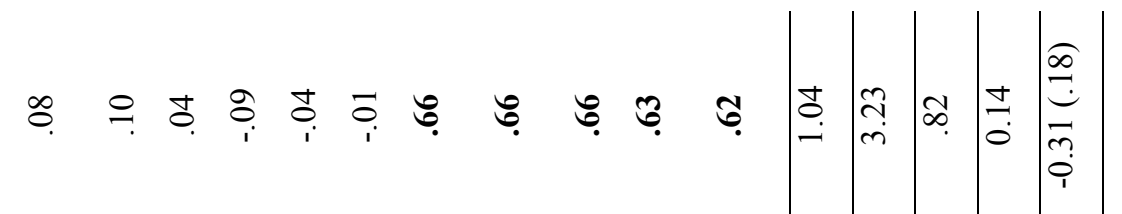

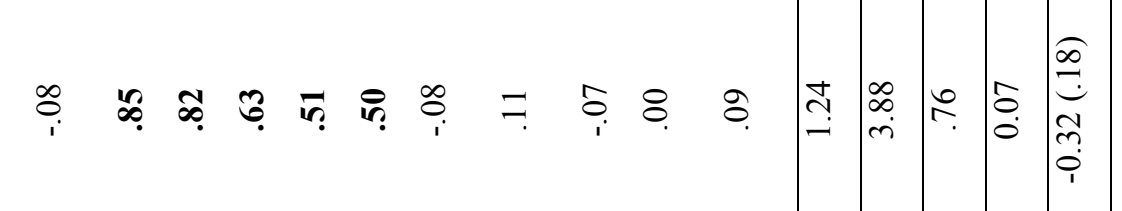

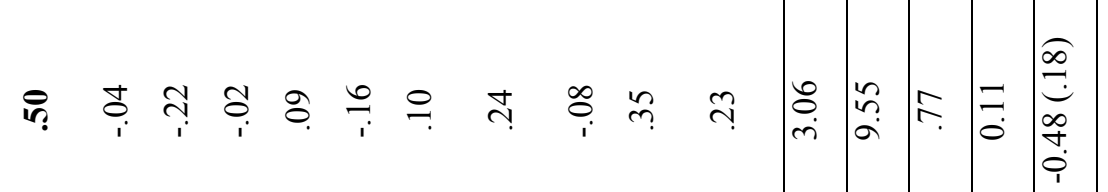

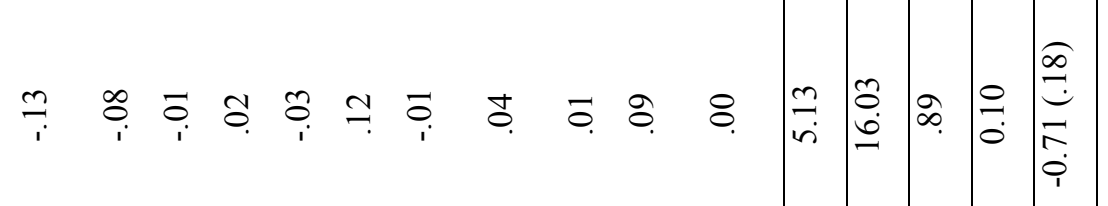

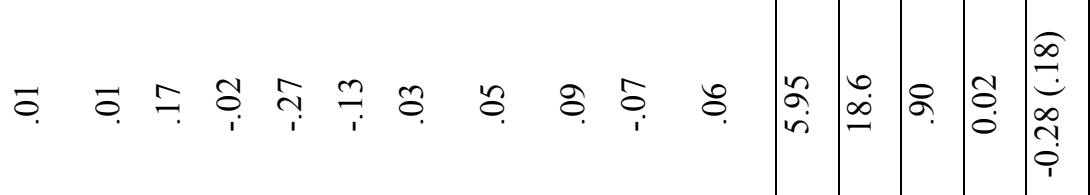

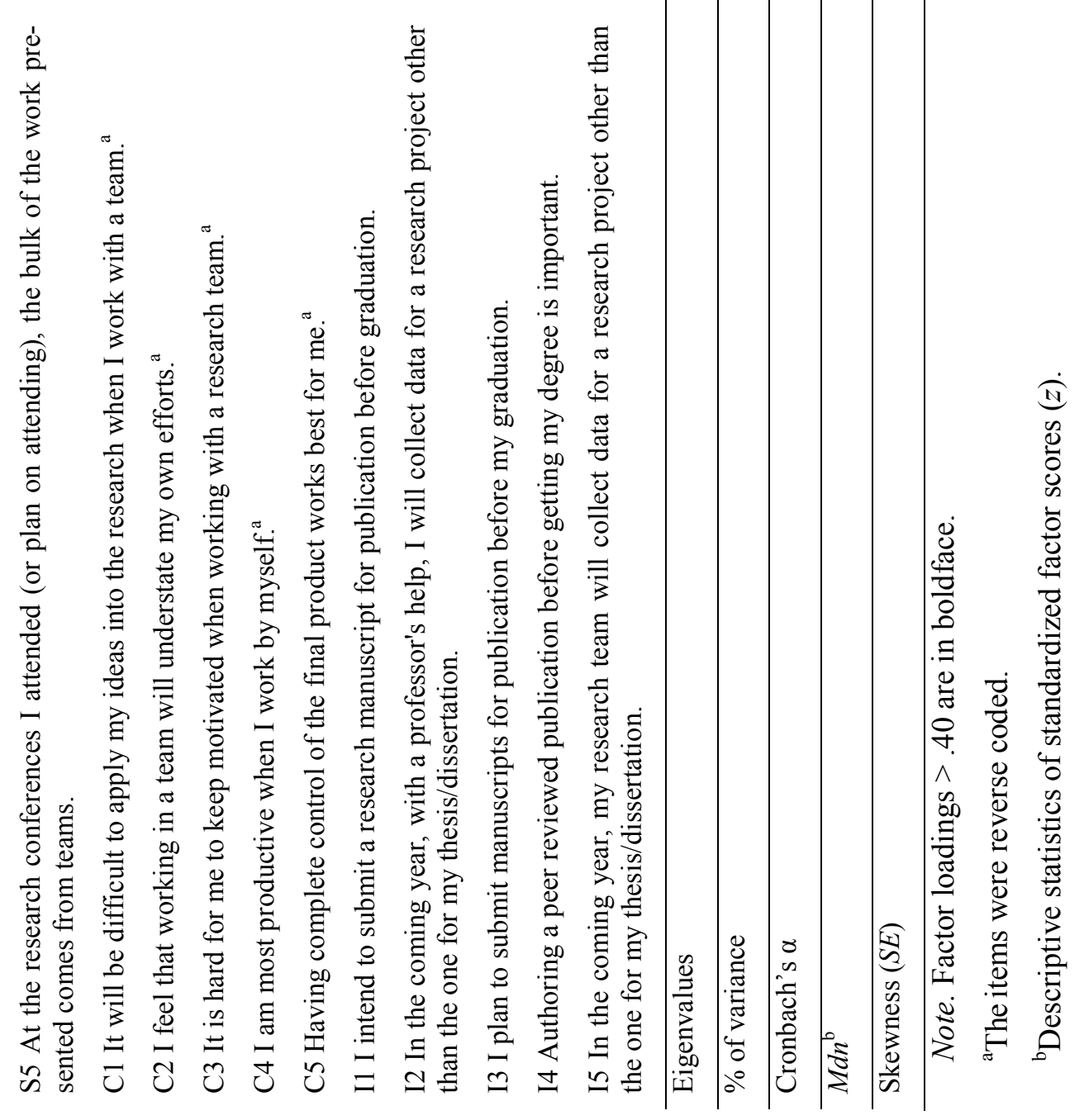


A confirmatory factor analysis (CFA) was then conducted based on the five-factor EFA solution with 32 items using Mplus v7 (Muthén \& Muthén, 2012). According to Brown (2006), CFA is used in later phases of instrument development after the underlying structure has been established on prior empirical (EFA) grounds. The acceptable model fit for CFA was defined by $\mathrm{Hu}$ and Bentler's (1999) combinational rules: (a) Comparative Fit Index (CFI) or Tucker-Lewis Index (TLI) $>0.95$ and Standardized Root Mean Square Residual $($ SRMR) $<.09$, or (b) Root Mean Square Error of Approximation (RMSEA) $<.05$ and SRMR $<.06$. Because Mplus provides Weighted Root Mean Square Residual (WRMR) instead of SRMR when the robust weighted least squares estimator (WLSMV) is activated, the cutoff value of WRMR $<1.0(\mathrm{Yu}, 2002)$ was also consulted. The initial CFA model did not indicate a good fit to the data, $\chi^{2}(424)=1220.52, p$ $<.0001, \mathrm{CFI}=.780, \mathrm{TLI}=.759, \mathrm{RMSEA}=.085,90 \% \mathrm{CI}[.080, .091]$. We consulted modification indices (MIs) (Sörbom, 1989) and identified the main source of poor-fitting to be corrected errors (Brown, 2006). For example, the correlated errors between Items AT1 and AT2 (see Table 1) produced the largest $\Delta \chi^{2}=48.97$, and the correlated errors between Items AT1 and AT3 produced the second largest $\Delta \chi^{2}=37.77$. Given the very similar wording of these items, we deleted items with lower factor loadings to minimize the influence of correlated errors without impairing much of the measurement validity. As a result, Items AI1, AI4, AI5, AI6, AT1, AT2, AT9, S3, S4, C4, I1, I3, and I4 (see Table 1) were removed, resulting in an acceptable measurement model: $\chi^{2}(125)=186.49, p=.0003, \mathrm{CFI}=.957, \mathrm{TLI}=.947, \mathrm{RMSEA}=.044,90 \% \mathrm{CI}[.030, .056]$, $\mathrm{SRMR}=.053$. This final measurement model retained $18(40 \%)$ of the original 45 items. Using Gorsuch's (1983) criteria for validity coefficients $(\geq .80)$, factor determinacy scores indicate that all four factors are well measured: Attitude towards Individual Research (three items) $=.99$, Attitude towards Team Research $($ six items $)=.94$, Subjective Norm $($ three items $)=.85$, Perceived Behavioral Control (four items) $=.89$, and Intention (two items) $=.92$.

\section{Correlations}

Zero-order correlations were computed among the five factors based on the 18 -item measurement model. As shown in Table 2, graduate students' attitudes towards individual research positively correlated with both their attitudes towards team research $(r=.17, p=.02)$ and their intentions to produce research $(r=.23, p<.01)$. Their attitudes towards team research, as expected, also positively correlated with other TPB factors: Subjective Norm $(r=.38, p<.001)$, Perceived Behavioral Control $(r=.54, p<.001)$, and Intention $(r=.29, p<.001)$. However, Perceived Behavioral Control only significantly correlated with Attitude towards Team Research $(r=.54, p<.001)$, but not with other factors.

Table 2. Zero-order Correlations among Five Factors in the Measurement Model

\begin{tabular}{llcccc}
\hline & 1 & 2 & 3 & 4 & 5 \\
\hline 1. Attitude towards Individual Research & -- & & & & \\
2. Attitude towards Team Research & $.17^{*}$ & -- & & & \\
3. Subjective Norm & -.13 & $.38^{* * *}$ & -- & & \\
4. Perceived Behavioral Control & -.13 & $.54^{* * *}$ & .13 & -- & \\
5. Intention & $.23^{* *}$ & $.29^{* * *}$ & $.41^{* * *}$ & .03 & -- \\
${ }^{*}$ & & & & &
\end{tabular}

${ }^{*} p<.05 .{ }^{* *} p<.01 .{ }^{* * *} p<.001$.

\section{The TPB Model}

Our last step was to fit the TPB model (Ajzen, 1991) to the data using structural equation modeling (SEM) in Mplus v7 (Muthén \& Muthén, 2012). Because Attitude towards Individual Re- 
search only bears relevance to individual research but not team research, we excluded it while retained the other four factors in the model, with both Intention and Behavior (i.e., number of coauthored manuscripts) being the outcome factors. Due to a lack of variance and the severe skewness of Behavior, we recoded Behavior into a dichotomous variable where 0 indicates no coauthored manuscripts at all, and 1 indicates having at least one co-authored submission. As such, the regression to Behavior is modeled as a probit regression. In addition, two covariates were also included in the model: classification and discipline. To account for the disparity between master's and doctoral students with regard to their research intensity, classification was dummy coded as master' $\mathrm{s}=0$ and doctoral $=1$, whereas discipline was coded as education $=-1$, engineering $=1$, others $=0$ in order to contrast education and engineering for the disciplinary effects.

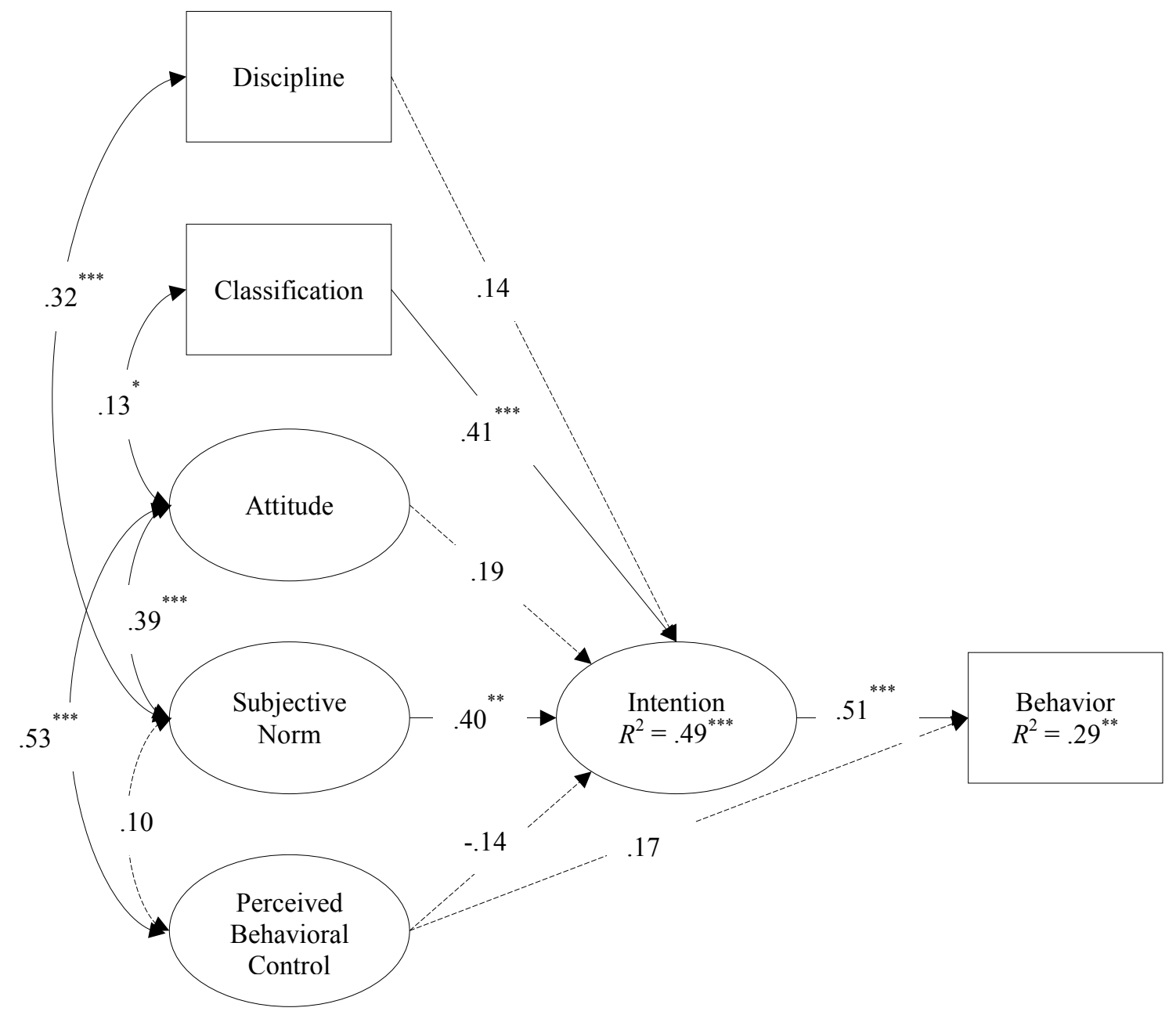

Figure 1. Final TPB model with estimated regression coefficients.

Note. Dashed lines denote hypothesized relations that are non-significant ("ns"). ${ }^{*} p<.05 .{ }^{* *} p<.01 .{ }^{* * *} p<.001$.

Figure 1 presents the final model with regression parameters. This final model fit the data well: $\chi^{2}(126)=187.73, p=.0003, \mathrm{CFI}=0.91, \mathrm{RMSEA}=.042,90 \%$ CI $[.029, .054], \mathrm{WRMR}=0.81$. The correlations of the two covariates with the TPB factors are worth noting: discipline only significantly correlated with Subjective Norm $(r=.32, p<.001)$, but not other factors, while classification only correlated with Attitude toward Team Research $(r=.13, p=.03)$. In other words, graduate students of engineering majors rated Subjective Norm items significantly higher than students of education majors, but the two disciplines do not differ significantly in Attitude or Per- 
ceived Behavioral Control. On the other hand, doctoral students tend to have more positive attitudes than master's students towards team research, but master's and doctoral students do not differ in Subjective Norm and Perceived Behavioral Control. In addition, classification $(\beta=.41, p<$ $.001)$ appears to have a significant impact on Intention, while discipline $(\beta=.14, p=.14)$ does not. Finally, the model explains $49 \%$ of the variance in Intention $(p<.001)$ and $29 \%$ of the variance in Behavior $(p=.001)$. While Intention is shown to be a significant predictor of Behavior ( $\beta$ $=.51, p<.001)$, Perceived Behavioral Control is not $(\beta=.18, p=.07)$.

\section{Discussion}

Our quantitative investigations of graduate students' attitudes towards team research yield meaningful results that are worth discussing. First and foremost, the descriptive statistics do not indicate high scholarly productivity among graduate students in terms of collaborative research. Particularly, the data are severely skewed with around two-thirds of students having no co-authored manuscripts during their graduate study. Considering the general turnaround for publishing an academic article, a median of 0 manuscript suggests that a large proportion of graduate students may not have any co-authored publication by the time they graduate. Such low scholarly productivity is barely investigated in the literature, but research on graduate students' development may shed some light on it. Whitley, Oddi, and Terrell (1998) found that factors that influence publication efforts of graduate students include academic requirements, faculty involvement and support, and the ability to self-select the research topic. Other findings echoed Whitley et al. (1998) that graduate students' scholarly productivity may be explained by both program- and personal-level characteristics. For example, Cuthbert and Spark's (2008) Australia-based observation indicates that that there is a lack of graduate publication programs, which is partly due to "a lack of clarity in universities about what the outcomes of graduate research education should be" (p. 78); while an early study by Hogan (1986) indicated that both the quality of entering students and the faculty publishing performance are positively correlated with students' publishing performance. Evans (2009) noted that developing a research culture and developing researchers are two inter-related components of developing institutional research capacity. Because this interrelation may be interpreted statistically that individual researchers are nested within their academic institutions, future studies may consider using multilevel models to account for graduate students' scholarly output.

With respect to the theory of planned behavior (TPB), the findings of structural equation modeling partly support our hypotheses. First, in contrast to our hypothesis, graduate students' attitudes towards individual research and team research have a direct, rather than inverse, relationship. This indicates that graduate students may appreciate the values of individual research and team research simultaneously, and that they will not likely shy away from research teams in favor of conducting research individually. In fact, the zero-order correlation between Attitude toward Individual Research and Intention is also significantly positive, indicating that graduate students are more likely to join research teams when they have positive appraisals of individual research. Second, the final TPB model accounts for $49 \%$ of the variance in Intention, which appears to be of a higher predictive accuracy than what has been reported (39-42\%);(see Armitage \& Conner, 2001; Cooke \& Sheeran, 2004). However, we must note the significant contributions of the covariates, given that removing these covariates would have reduced the $R^{2}$ to $26 \%$. These findings highlight the disparity between master's and doctoral students in terms of their research intensity, as well as a disciplinary effect in determining graduate students' research intentions. Master's students, while perceiving similar levels of pressure to do team research as their doctoral counterparts, demonstrate significantly lower intentions to do so. In terms of the disciplinary effect, we found it to be evident only in Subjective Norm. This finding is not surprising given that each discipline may have its unique norms in conducting research. As compared with students of education, engineering students appear to perceive higher social pressure to join research teams, proba- 
bly due to that they are more used to the scene of large-scale collaborative research (Austin, 2002). On the other hand, students' appraisals and intentions about team research do not seem to differ according to their disciplines. Third, the role of Perceived Behavioral Control in the model is well worth some discussion: while Perceived Behavioral Control positively correlates with Attitude towards Team Research in the model $(r=.53, p<.001)$, none of its relationships with Subjective norm, Intention, or Behavior is significant. In other words, graduate students who have positive evaluations about team research will also perceive it easier to do research with teams (i.e., they will be more confident in their capabilities of conducting team research); however, those who perceive higher levels of social pressure to join research teams (e.g., "In my field, people usually conduct research in teams") will not likely be more confident about their capabilities to collaborate with others on research. Fourth, attitude and perceived social pressure do not appear to be equally substantial in predicting Intention. This seems to that students' decisions on how they conduct research are mainly influenced by the norms in their academic programs, rather than their appraisals of collaborative research or the evaluations of their own capabilities. Although Ajzen (1991) argued that adding Perceived Behavioral Control enhances predictive accuracy of the TPB, this does not seem to be the case with team research.

We provide two alternative explanations for the inverse relationship of Perceived Behavioral Control and Intention $(\beta=-.14, p=.26)$. First, there may be a suppression effect (Cohen, Cohen, West, \& Aiken, 2003) which strengthens the relationship between Perceived Behavioral Control and Intention. We need to note that such a strengthened association is statistically noticeable yet conceptually meaningless (Feng \& Wilson, 2007). The second explanation is of a conceptual perspective: low levels of confidence in conducting team research (low Perceived Behavioral Control) may also indicate lack of confidence in general research activities. Many coping models indicate that individuals' perception of stressful situations may influence their coping responses (e.g., support seeking, avoidance; Olff, Langeland, \& Gersons, 2005; Renner, Spivak, Kwon, \& Schwarzer, 2007; Yeh, Arora, \& Wu, 2006). Hence, it may be that graduate students with lower levels of confidence are more likely to find ways such as joining research teams to compensate for their weaknesses. This may also explain why Perceived Behavioral Control is of little contribution in the final TPB model.

\section{Conclusion}

Our findings provide implications for graduate programs that are determined to promote graduate students' research. Previous studies have demonstrated the benefits of collaborative research (Hilvers, 2012; Ordóñez-Matamoros, Cozzens, \& Garcia, 2010), and graduate programs may work hard to encourage team research. The TPB postulates that, in addition to acknowledging the value of a certain task and expecting positive outcomes of it, one also needs to be confident in his capabilities to successfully perform the task. This does not hold in our analysis because graduate students' intentions to join research teams are not affected by their levels of confidence. This may be good news to program chairs or other decision-makers that perceived difficulties or struggles (e.g., authorship issues, conflicts of ideas) will not likely thwart students' intentions to join research teams. Rather, it is of much importance to create a climate of collaborative research as well as to enhance graduate students' appraisals of such collaborations. In fact, these two may have a reciprocal relationship given their moderate positive correlation. When more research teams are built in the department, particularly when the teams start to produce research, graduate students will likely show higher intentions to join the teams despite that they may not be motivated to start a research project individually. Faculty members need to supervise the teams to bring expertise to novice researchers, and the presence of faculty members also contributes to departmental climate for collaboration (Hilvers, 2012). In order to promote team research among graduate students, it may be particularly helpful to build research team exemplars with effective faculty support. 
Several limitations must be noted about this study. First, the TPB instrument has not been used in previous studies, which naturally leads to concerns of its external validity. The internal consistency reliabilities of some factors are barely acceptable, which has possibly impaired the predictive accuracy of the model. The instrument needs further revisions before being utilized for future studies. The score distributions tend to be negatively skewed for most items, indicating that the item thresholds may be too low. We consider a Rasch model (de Ayala, 2009) particularly helpful in identifying this potential issue. Second, given the breakdown of disciplines (primarily education and engineering), our sample may be homogeneous in terms of how they define and conduct research. Although early studies in a particular area may benefit from a homogenous sample for better control of confounding variables, the generalizability of our findings may be limited. Future studies need to include other disciplines such as history, English, and other STEM disciplines which may largely expand our understandings of graduate students' team research. Finally, number of co-authored manuscripts may not be the most accurate measure of behaviors when behavior is defined as the manifest, observable response in a given situation in Ajzen's (1991) model. Because the present study is not longitudinal by nature, we were unable to capture changes in behaviors after we measure participants' intentions, nor could we conduct a qualitative follow-up study to further explore the mechanisms underlying our findings. We collected exiting numbers of publications based on Ajzen's (1991) suggestion that single behavioral observations can be aggregated across times to produce a more broadly representative measure, though a follow-up study to measure their publications in next few years is desirable. Future studies may consider longitudinal designs to overcome this limitation. Furthermore, number of co-authored submissions, though being a relatively objective measure, does not capture other indicators of publishing performance such as workload, individual contribution, order of authorship, or quality of the publication. Some of these indicators may be quantified while others may not be, mixed-methods approaches may also be appropriate for future investigations in this area. Specifically, an explanatory sequential mixed-methods design where quantitative data collection and analysis is followed by qualitative inquiries and interpretations (Creswell \& Plano-Clark, 2011) may be particularly meaningful for explaining the theoretical questions reflected in the current study.

\section{Acknowledgement}

This research was supported by a grant from the College of Education, Texas Tech University.

\section{References}

Ajzen, I. (1988). Attitudes, personality, and behavior. Milton Keynes, England: Open University Press.

Ajzen, I. (1991). The theory of planned behavior. Organizational Behavior and Human Decision Processes, 50, 179-211.

Ajzen, I., \& Fishbein, M. (1980). Understanding attitudes and predicting social behavior. Englewood Cliff, NJ: Prentice-Hall.

Armitage, C. J., \& Conner, M. (2001). Efficacy of the theory of planned behaviour: A meta-analytic review. British Journal of Social Psychology, 40, 471-499.

Atkinson, J. W. (1964). An introduction to motivation. Princeton, NJ: Van Nostrand.

Austin, A. E. (2002). Preparing the next generation of faculty: Graduate school at socialization to the academic career. Journal of Higher Education, 73(1), 94-122.

Bandura, A. (1977). Self-efficacy: Toward a unifying theory of behavioral change. Psychological Review, $84,191-215$.

Bandura, A. (1982). Self-efficacy mechanism in human agency. American Psychologist, 37, 122-147. 
Bandura, A. (1986). Social foundations of thought and action: A social cognitive theory. Englewood Cliffs, NJ: Prentice Hall.

Bandura, A. (1997). Self-efficacy: The exercise control. New York, NY: Freeman.

Barrick, R. K., Easterly, R. G., \& Rieger, M. W. (2011). Assessment of graduate student productivity and satisfaction. NACTA Journal, 55(2), 54-60.

Becher, T. (1984). The cultural view. In B. R. Clark (Ed.), Perspectives on higher education: Eight disciplinary and comparative views (pp. 165-194). Berkeley and Los Angeles, CA: University of California Press.

Blackburn, R. T., Behymer, C. E., \& Hall, D. E. (1978). Research notes: Correlates of faculty publication. Sociology of Education, 51, 132-141.

Bland, C. J., \& Ruffin, M. T. (1992). Characteristics of a productive research environment: Literature review. Academic Medicine, 67(6), 385-397.

Bland, C. J., \& Schmitz, C. C. (1986). Characteristics of the successful researcher and implications for faculty development. Journal of Medical Education, 19(1), 22-31.

Blumer, M. L., Green, M. S., \& Palmanteer, D. (2007). Creating a collaborative research team: Feminist reflections. Journal of Feminist Family Therapy, 19(1), 41-55.

Bourke, S., \& Holbrook, A. (2013). Examining PhD and research masters theses. Assessment and Evaluation in Higher Education, 38(4), 407-416.

Brown, T. A. (2006). Confirmatory factor analysis for applied research. New York, NY: Guilford.

Bryan, L., Negretti, M., Christensen, F. B., \& Stokes, S. (2002). Processing the process: One research team's experience of a collaborative research project. Contemporary Family Therapy, 24(2), 333-353.

Cameron, S. W., \& Blackburn, R. T. (1981). Sponsorship and academic career success. Journal of Higher Education, 52(4), 369-377.

Clark, B. R. (1987). The academic profession. Berkeley, CA: University of California Press.

Clark, S. M., \& Corcoran, M. (1985). Individual and organizational contributions to faculty vitality: An institutional case study. In S. M. Clark, \& D. R. Lewis (Eds.), Faculty vitality and institutional productivity: Critical perspectives for higher education (pp. 112-138). New York, NY: Teachers College Press.

Cohen, J., Cohen, P., West, S., \& Aiken, L. S. (2003). Applied multiple regression/correlation analysis for behavioral sciences. Hillsdale, NJ: Lawrence Erlbaum Associates.

Cook, R. D., \& Weisberg, S. (1982). Residuals and influence in regression. New York, NY: Chapman \& Hall.

Cooke, R., \& Sheeran, P. (2004). Moderation of cognition-intention and cognition-behaviour relations: A meta-analysis of properties of variables from the theory of planned behaviour. British Journal of Social Psychology, 43, 159-186.

Creswell, J. W., \& Plano-Clark, V. L. (2011). Choosing a mixed methods design. In J. W. Creswell, \& V. L. Plano-Clark, Designing and conducting mixed methods research (pp. 53-106). Thousand Oaks, CA: Sage.

Cuthbert, D., \& Spark, C. (2008). Getting a GRiP: Examining the outcomes of a pilot program to support graduate research students in writing for publication. Studies in Higher Education, 33(1), 77-88.

de Ayala, R. J. (2009). The theory and practice of item response theory. New York, NY: The Guilford Press.

Evans, L. (2009). Developing research capacity in the social sciences: A professionality based model. International Journal for Researcher Development, 1(2), 134-149. 
Feng, H., \& Wilson, S. R. (2007). An application of the theory of planned behavior to support provision behaviors across cultures. Paper presented for the Intercultural Communication Division of the National Communication Association, Chicago: IL.

Field, A. (2009). Discovering statistics using SPSS (3rd ed.). Thousand Oaks, CA: Sage Publications.

Fishbein, M., \& Ajzen, I. (2010). Predicting and changing behavior: The reasoned action approach. New York, NY: Psychology Press.

Fox, M. F. (1991). Gender, environmental milieu, and productivity in science. In H. Zuckerman, J. R. Cote, \& J. T. Bruer (Eds.), The outer circle: Women in scientific community (pp. 188-204). New York, NY: W. W. Norton.

Gorsuch, R. L. (1983). Factor analysis (2nd ed.). Hillsdale, NJ: Erlbaum.

Gorsuch, R. L. (1997). Exploratory factor analysis: Its role in item analysis. Journal of Personality Assessment, 68(3), 532-560.

Hilvers, J. (2012). Setting graduate education path for public sociology. In P. Nyden, L. Hossfeld, \& G. Nyden (Eds.), Public sociology: Research, action, and change (pp. 20-26). Thousand Oaks, CA: Pine Forge Press/Sage Publications.

Hogan, T. D. (1986). The publishing performance of U.S. Ph.D. programs in economics during the 1970s. Journal of Human Resources, 21(2), 216-229.

Hu, L., \& Bentler, P. M. (1999). Cutoff criteria for fit indexes in covariance structure analysis: Conventional criteria versus new alternatives. Structural Equation Modeling, 6, 1-55.

Hulse-Killacky, D., \& Robison, F. F. (2005). An effective research team method to influence research and scholarly development. The Journal for Specialists in Group Work, 30(3), 241-252.

Hutcheson, G., \& Sofroniou, N. (1999). The multivariate social scientist. London, UK: Sage.

Jassawala, A. R., \& Sashittal, H. C. (1998). An examination of collaboration in high-technology new product development processes. Journal of Product Innovation Management, 15, 237-254.

Kaiser, H. F. (1960). The application of electronic computers to factor analysis. Educational and Psychological Measurement, 20, 141-151.

Lee, T. W., \& Mitchell, T. R. (2011). Working in research teams: Lessons from personal experiences. Management and Organization Review, 7(3), 461-469.

Lei, S. A., \& Chuang, N. K. (2009). Research collaboration and publication during graduate studies: Evaluating benefits and costs from students' perspectives. College Student Journal, 43(4), 1163-1168.

Li, Z., Zhu, T., \& Wang, H. (2010). A study on the influencing factors of the intention to share tacit knowledge in the university research team. Journal of Software, 5(5), 538-545.

Moore, M., Tatum, B. C., \& Sebetan, I. (2011). Graduate education: What matters most? Journal of Research in Innovative Teaching, 4(1), 65-77.

Muthén, L. K., \& Muthén, B. O. (2012). Mplus user's guide (7th ed.). Los Angeles, CA: Muthén \& Muthén.

Olff, M., Langeland, W., \& Gersons, B. P. (2005). Effects of appraisal and coping on the neuroendocrine response to extreme stress. Neuroscience and Biobehavioral Reviews, 29, 457-467.

Ordóñez-Matamoros, H. G., Cozzens, S. E., \& Garcia, M. (2010). International co-authorship and research team performance in Columbia. Review of Policy Research, 27(4), 415-431.

Posselt, J. R., \& Black, K. R. (2012). Developing the research identities and aspirations of first-generation college students: Evidence from the McNair scholars program. International Journal for Researcher Development, 3(1), 26-48.

Renner, B., Spivak, Y., Kwon, S., \& Schwarzer, R. (2007). Does age make a difference? Predicting physical activity. Psychology and Aging, 22, 482-493. 
Sörbom, D. (1989). Model modification. Psychomertika, 54, 371-384.

Turner, M. M. (2006). The research team concept, II: (Still) an approach to graduate training. Community Research Reports, 23(3), 225-230.

Waldron, V., Shattuck, R., Zimbrick, D., Finter, L., \& Edwards, P. (2007). Community research team: An experiment in member-driven research and reflection. LLI Review, 2, 44-53.

Wan Mohamed, M. F., Omar, Z., Ahmad, A., \& Juned, R. (2012). Critical factors influencing the effectiveness of research teams among academicians. Social Sciences and Humanities, 20(3), 695-706.

Whitley, G. G., Oddi, L. F., \& Terrell, D. (1998). Factors influencing the publishing efforts of graduate students in nursing. Journal of Nursing Education, 37(4), 182-185.

Yeh, C. J., Arora, A. K., \& Wu, K. A. (2006). A new theoretical model of collectivistic coping. In P. T. Wong, \& L. C. Wong (Eds.), Handbook of multicultural perspectives on stress coping (pp. 55-72). Dallas, TX: Spring Publications.

Yu, C. (2002). Evaluating cutoff criteria of model fit indices for latent variable models with binary and continuous outcomes. (Doctoral dissertation). University of California, Los Angeles.

Zimmerman, B. J., \& Schunk, D. H. (2003). Albert Bandura: The scholar and his contributions to educational psychology. In B. J. Zimmerman, \& D. H. Schunk (Eds.), Educational Psychology: A Century of Contributions (pp. 431-457). Mahwah, NJ: Lawrence Erlbaum Associates.

\section{Biographies}

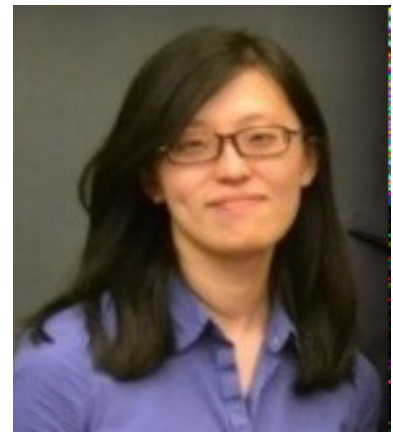

Dr. Tianlan Wei is an Assistant Professor of Educational Psychology in Department of Counseling and Educational Psychology, Mississippi State University. She received her Bachelor's degree in Law from Fudan University, China and her M.Ed. and Ph.D. in Educational Psychology from Texas Tech University. Her research interests involve gender differences/issues in learning and performance, academic interest and affect in educational settings, and evaluation of psychometric properties of educational measurements.

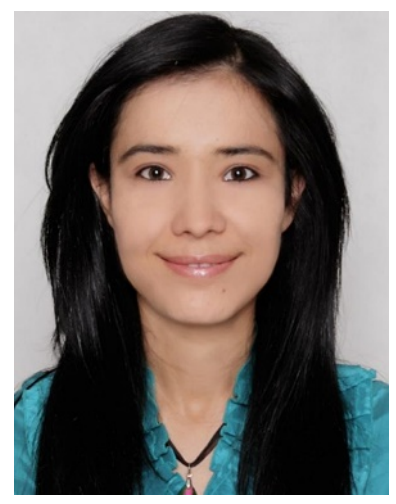

Dr. Alime Sadikova is an Assistant Principal at South Hills High School at Fort Worth ISD. She began her career as a high school teacher in 1997. In 2001, she became the founder and principal of the private school named Encourse located in her home country, where she worked for five years. During that time, Dr. Sadikova was one of the top ten principals in the nation, ultimately providing her first opportunity to visit the United States and attend leadership training in Minnesota. In 2006, Dr. Sadikova returned to the United States as a Fulbright Scholar and earned three degrees from Texas Tech University: Masters degrees in Applied Linguistics and Educational Leadership; and Doctoral degree in Educational Leadership. At Texas Tech, she also worked as research assistant for six years and was a president of Education Graduate Student Organization for 2 years. Dr. Sadikova truly believes that every high school graduate is college and career bound and will do her best to help students realize his or her potential. 


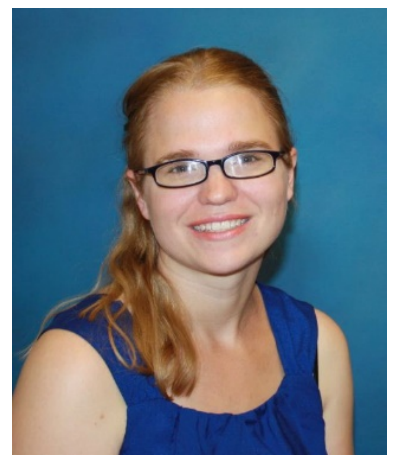

Dr. Lucy Barnard-Brak is an Associate Professor in the Educational Psychology program, Texas Tech University. Her research currently focuses measurement and assessment issues for vulnerable populations, especially individuals with disabilities. She currently enjoys refining the application of item response theory models and the comparison of ROC curves to data from special populations.

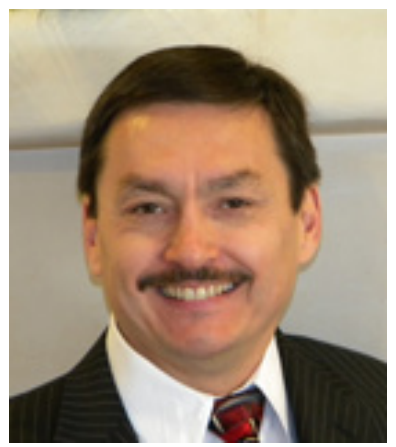

Dr. Eugene Wang is an Associate Professor in Educational Psychology at Texas Tech University, and serves as the Program Coordinator for the Research, Evaluation, Measurement, and Statistics (REMS) concentration. He is also the Associate Director of the Institute for Measurement, Methodology, Analysis, and Policy (IMMAP). He received his Bachelor's and Master's degrees in Psychology from East Texas State University and his Ph.D. in Psychology from Texas A\&MCommerce. His research areas have a broad focus on individuals with emotional and behavioral disorders, assessment of risk (particularly violence risk), and strategies for reducing interpersonal violence. He is particularly interested in implementation of positive behavioral interventions and supports (PBIS) in at-risk populations, such as incarcerated youth.

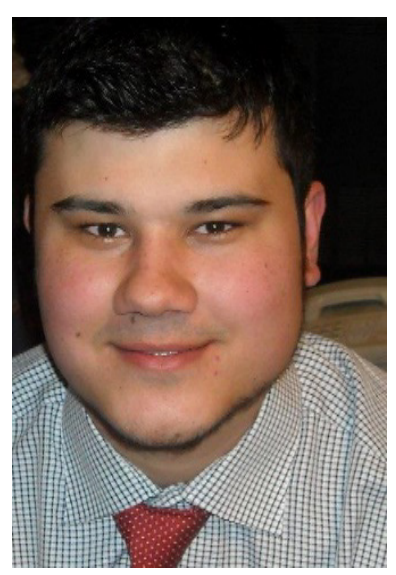

Dilshod Sodikov is social studies middle school teacher at Academy of Dallas. He earned his Bachelor's degree in English and Master's degree in Educational Psychology from Texas Tech University. He also worked as a research assistant at the same university for two years. Prior to this, he worked as social studies high school teacher in Uzbekistan. 